\title{
Carla Gras \\ Elites rurales contemporáneas: cambio tecnológico, liderazgo empresarial y acción política en la Argentina sojera ${ }^{1}$
}

\section{Introducción}

Las ciencias sociales en Argentina ofrecen una cartografía pormenorizada de las mutaciones que conocieron su estructura social y las identidades sociales y políticas de distintos actores en las últimas décadas. En esa cartografía, el estudio de las transformaciones ocurridas entre los sectores económica y socialmente predominantes ha ocupado un lugar relativamente menor en comparación con el abordaje de los sectores populares o de las clases medias (Heredia 2005). Al mismo tiempo, se observa la persistencia de ciertos supuestos referidos a la coherencia entre los intereses de estos sectores y su posición económica, y al papel casi excluyente que los intereses económicos tienen en sus formas de organización y presencia en la vida pública y política.

En el caso de las elites rurales, estos supuestos asumen formas bien precisas. Así, se da por descontada la relación entre su liberalismo económico, su oposición acérrima a toda forma de regulación o posicionamiento por parte del Estado frente a las condiciones que sustentan su dinámica de acumulación, y sus formas de organización y presión en el espacio público. Asimismo, se presume su naturaleza anti-democrática tanto en lo que refiere a sus valores y creencias políticas como al tipo de arreglos institucionales que propician para defender sus intereses. Con las reformas de mercado y del Estado en los

1 Una versión anterior fue presentada al Taller "El Bicentenario de la independencia y la(s) democracia(s) en América Latina”, realizado el 12 y 13 de Febrero de 2010 en Berlín. La revisión y ampliación de la misma se vio beneficiada por los comentarios allí recibidos. Agradezco especialmente la atenta lectura y aportes de Claudia Lozano. Este trabajo fue elaborado en el marco de la estadía de investigación en el Lateinamerika-Institut, Freie Universität Berlin y el IberoAmerikanisches Institut, financiada por una beca de la Fundación Alexander von Humboldt. 
años '90 y el desarrollo de un nuevo patrón socio productivo en el agro -que dio lugar a una mayor concentración de la tierra y la producción, y a una intensificación de la capitalización- la pregunta sobre cómo el poderío económico de los sectores beneficiados se reflejaba en la política pública pareció perder relevancia, al darse por supuesto que esa traducción operaba sin fallas.

En este trabajo proponemos dialogar con estas asunciones, interrogándonos por los comportamientos políticos de las elites rurales en la Argentina contemporánea. Desde mediados del siglo XIX, el peso económico, social y político de los grandes productores ha sido fundamental en la historia del país. Si bien la importancia de la producción agropecuaria en términos de su contribución a la economía nacional ha conocido distintos momentos, cabe destacar su dinámica de crecimiento en las últimas dos décadas, proceso asociado al cambio técnico y a la biotecnología. Desde distintos enfoques disciplinarios, numerosos estudios han analizado la relación entre la expansión de cultivos transgénicos -con sus impactos en la organización y gestión de los procesos de trabajo, las demandas de capital y conocimientos, etc. - y los profundos cambios en la estructura productiva y social del agro argentino. En otros trabajos, hemos subrayado cómo ese patrón tecnológico demandó nuevos modos de entender y practicar la actividad agropecuaria, favoreciendo el ingreso de nuevos actores, obligando a unos a cambiar sus prácticas, y expulsando a un número no menor de otros (Gras/Hernández 2008). Menos se conoce acerca de la medida en que esos cambios tecnológicos y sociales se expresan en los comportamientos políticos de los actores que adquirieron posiciones relevantes a partir de los mismos. Nuestra hipótesis es que el cambio técnico ha sido vehículo también de transformaciones en sus identidades (sus representaciones, ideas y creencias respecto de lo que son) y que ello tiene consecuencias en sus modalidades de presencia en la vida pública y política, demandas y formas de acción.

Estas preocupaciones cobran relevancia en el contexto actual gracias a la conjunción de una serie de factores. Entre ellos, uno de los más importantes y quizá menos problematizado refiere a la recomposición de la propia elite, tanto en lo que refiere a los perfiles como a las trayectorias y orígenes sociales de quienes hoy integran las capas superiores de la estructura agraria. Un segundo factor es la complejización de las formas de representación de intereses donde las orga- 
nizaciones tradicionales de carácter gremial coexisten con asociaciones profesionales. Estas últimas conforman verdaderas traductoras de los valores e ideas respecto de las bondades del cambio técnico, y del nuevo tipo empresarial que el mismo requiere, constituyéndose en nexos que permiten articular comportamientos productivos, económicos, sociales y políticos de maneras significativas para los actores. Además, muchas veces han sido más eficaces para influir en decisiones de política pública, logrando concitar mayor adhesión entre la elite que las corporaciones que históricamente se arrogaron su representación. Nos interesa explorar aquí las modalidades que asume la presencia de las elites en la vida pública y política -en particular en su relación con el Estado -a partir de constatar esa diversificación de formas de agregación y representación de intereses. Finalmente, nos interesa abordar la dimensión política, centrándonos en la producción de ideas y nociones que movilizan su accionar, moldeando el modo en que perciben sus intereses y su posición en la sociedad. ${ }^{2}$ Para ello, tomaremos como caso de análisis el reciente conflicto entre los productores agrarios y el gobierno de Cristina F. de Kirchner por la política de derechos a las exportaciones (retenciones). Como observamos en nuestra investigación, ${ }^{3}$ el mismo fue un momento de debate político al interior de la elite en el que se fueron (re)construyendo núcleos de sentido respecto de su papel en el sector agropecuario y en la sociedad más amplia, su relación con los sectores subordinados (agrarios y no agrarios), con el Estado, etc. Sostendremos que en el marco del conflicto se pusieron en juego estas otras dimensiones además de la presión corporativa en torno a una medida desfavorable para el sector agropecuario -que perjudicaba los niveles de

2 La historiografía se ha ocupado profusamente de estas cuestiones, en especial para el período que va desde la conformación del Estado nacional hacia mediados del siglo XIX hasta la $1^{\circ}$ Guerra Mundial. En ese marco, el trabajo de Hora (2009) resultó particularmente inspirador para situar los interrogantes de mi investigación en perspectiva histórica.

3 En el marco de mi investigación actual ("Dinámicas sociales y políticas en el nuevo escenario agrario: actores, prácticas institucionales y representaciones ideológicas"), me he centrado en la indagación sobre las nuevas formas de acción política de la burguesía agraria en el período post 2001. Mi abordaje es el de estudios de caso, utilizando entrevistas, documentos institucionales, material periodístico y la observación no participante de distintos espacios de interacción como asambleas y seminarios. 
ganancia de la elite- y se planteó la necesidad de darle a ello una expresión política.

\section{El agro argentino y sus actores principales}

Desde mediados del siglo XIX la dinámica del sector agropecuario estuvo entrelazada con la posición dominante de un conjunto de grandes terratenientes capitalistas asentados en la región pampeana, principal productora de los bienes exportables (carne y cereales) sobre los que se asentó la integración del país al mercado internacional. Como señala Hora (2009), el lugar de privilegio de estos grupos no solo se sustentaba en la propiedad de amplios volúmenes de tierra que controlaban, sino también en su carácter innovador en lo que respecta a los métodos de producción. Así, según el autor, estos grupos combinaban dos características: poderío económico y dinamismo empresarial.

La crisis mundial de 1929 introdujo inflexiones importantes en el modelo económico, iniciándose un proceso de sustitución de importaciones que, aunque complejizó la morfología social del país, no transformó sustantivamente las bases de la posición dominante de estos terratenientes. Con la profundización del proceso de industrialización, el poder de esta elite fue diezmándose, tanto por la importancia que cobraban los sectores industriales, como por la consolidación de pequeños y medianos agricultores, beneficiados por políticas de acceso a la propiedad de la tierra y al crédito durante el primer peronismo. No obstante, los grandes productores retendrían una cuota significativa de poder al controlar el principal canal de obtención de divisas del país, el que a su vez jugaba un rol sustantivo en el proceso de industrialización, al ser esos mismos bienes parte básica de la canasta alimenticia de las clases trabajadoras. Como ha señalado O'Donnell (1977), aún cuando la elite agraria -junto con otras fracciones de la burguesía pampeana- ya no fuera el pivote central del capitalismo argentino, tenía la capacidad de defenderse de cualquier intento de reestructurarla ${ }^{4}$ así como de lograr transferencias de ingreso en su beneficio, en momentos en que la relación entre exportación/consumo interno derivaba en crisis de balanza de pagos. La vigencia del modelo

4 Por ejemplo, el intento en 1973 de sancionar un impuesto a la renta normal potencial de la tierra. 
de industrialización sustitutiva (hasta los años '70) sería también la etapa del llamado "estancamiento pampeano", caracterizada por la pérdida de dinamismo o retroceso de la producción de granos y de la ganadería vacuna ${ }^{5}$ (Obschatko 2003).

Posteriormente, la actividad agropecuaria comienza un proceso de cambio que le devolvería su rol protagónico en la economía argentina. Un elemento destacado en la evolución positiva de la producción y la productividad fue la incorporación de tecnologías -insumos industriales, semillas híbridas, mecanización de labore-, que se consolida en las últimas décadas con la expansión de la biotecnología. Ello tuvo impactos en el patrón productivo: se registra un creciente abandono relativo de la ganadería y el incremento de la producción de granos, especialmente de soja transgénica, que es exponencial desde $1995^{6}$. A diferencia de la carne y el trigo que se destinaron históricamente tanto al mercado mundial como al doméstico, la soja se exporta casi en su totalidad.

La utilización de un nuevo "paquete" tecnológico ${ }^{7}$ impulsó la intensificación en el uso del capital, modificando los umbrales mínimos para sostenerse en la producción. Así, durante toda la década de 1990 se registró un incremento sostenido del tamaño mínimo para una explotación rentable, proceso en el que también incidió la política ma-

5 Los debates políticos y académicos sobre esa etapa incorporaban factores tales como el comportamiento de los niveles de inversión y rentabilidad, su relación con las políticas de transferencia de la renta agropecuaria a otros sectores de la economía, así como también el carácter de las elites agropecuarias, en especial de los grandes ganaderos, visualizados por una parte significativa de la literatura como una clase oligárquica que vivía de la renta derivada de su control sobre la tierra.

6 En 1990 la superficie con soja rondaba los cinco millones de hectáreas, alcanzando los siete millones en 1997. Entre ese último año y 2009 la superficie sembrada con soja de hectáreas más que se duplicó, alcanzando los 18 millones. La producción tuvo un crecimiento aún más intenso, pasando de 18.732.172 toneladas en 1997 a cerca de 47 millones y medio en 2007. Las dos campañas siguientes registran caídas en la producción, como consecuencia, entre otros factores, de la sequía. En la última campaña (2009), la producción fue de casi $31 \mathrm{mi-}$ llones de toneladas (Estimaciones Agrícolas, Ministerio de Agricultura, Ganadería y Pesca de la Nación).

7 Es usual en la bibliografía local referirse al conjunto de innovaciones como "paquete" tecnológico para dar cuenta del modo en que ellas están concatenadas e implicadas unas con otras: la semilla transgénica con el glifosato, un tipo de tecnología de siembra (la siembra directa), de organización laboral, de gestión. 
croeconómica, modificando drásticamente la estructura de costos de las empresas. ${ }^{8}$

Los cambios no sólo afectaron a los pequeños y medianos agricultores, dejando a muchos de ellos afuera de la producción, ${ }^{9}$ sino también a empresarios de mayor tamaño. Lo que importa subrayar aquí es la transformación en el perfil de las capas empresariales y en especial de quienes ocupan los estratos superiores en términos de los recursos controlados. Se trata de un cambio importante que no solo refiere a la existencia de una franja "ganadora", que concentra mayores volúmenes de tierra y producción, sino también a las formas de control que ejercen sobre ellos y las relaciones que establecen tanto con actores poderosos (como las empresas transnacionales de semillas, los grandes exportadores) como con aquellos que ocupan posiciones de menor poder relativo (pequeños y medianos propietarios y/o productores, contratistas de maquinaria). El cambio en el perfil empresarial encuentra en los llamados pooles de siembra su expresión más acabada: se trata de empresas con acceso al capital financiero que manejan el know-how de gestión y el management que articula los distintos recursos del sistema, de los cuales uno de los más preciosos es la información y el saber experto para programar con anticipación más de un ciclo productivo. ${ }^{10}$ Así, a través de contratos formales e informales con distintos agentes gerencian cientos de miles de hectáreas, propias y/o alquiladas a terceros. Sin entrar en el debate sobre qué tipos de actores adoptaron esta forma de organización empresarial, cabe retener la complejización de las posiciones de los actores que lideran el sector agropecuario en Argentina, mediante relaciones donde la propiedad de la tierra -tradicional soporte de las elites agro-

8 La política neoliberal afectó especialmente al sector agropecuario: baste recordar la eliminación de casi todos los impuestos a las exportaciones; la supresión de aranceles a la importación de bienes de capital, lo que se tradujo en una renovación importante del parque de maquinarias; así como también la eliminación de casi todos los organismos reguladores y la privatización de los servicios públicos. Otro aspecto sustantivo fue la retracción del Estado del mercado financiero, lo que afectó el acceso al crédito.

9 Según datos de los censos agropecuarios entre 1988 y 2002 desaparecieron 88.000 explotaciones agropecuarias $(21 \%)$ y el tamaño promedio de las mismas aumentó un $25 \%$ para alcanzar 587 hectáreas en 2002.

10 Al respecto, véase Hernández (2007). 
pecuarias- y el capital se combina y/o deja lugar a otros vínculos y relaciones de producción.

En definitiva, al hablar hoy de grandes explotaciones agropecuarias estamos refiriendo a empresas que operan superficies superiores a las 5.000 hectáreas, que controlan bajo distintas formas de tenencia de la tierra y de relación con el capital, y modalidades de organización laboral. Según el Censo Agropecuario de 2002, estos estratos representaban el $2 \%$ del total de explotaciones agropecuarias y controlaban casi el $50 \%$ de la superficie cultivada. ${ }^{11}$ Según algunos estudios, la cúpula empresarial del sector agrario se ubica en los rangos de superficies superiores a las 20.000 hectáreas, incluyendo territorios en países limítrofes. La consolidación económica de esta burguesía y de la elite que la corona se hace evidente a partir de 2002 en una coyuntura que combina altos precios internacionales y una mejora sustantiva de los precios relativos del sector a partir de la aplicación de un nuevo régimen cambiario.

¿Cómo se relaciona el cambio en la morfología empresarial con la pregunta sobre la reproducción o recomposición de las elites agropecuarias? Es decir, ¿en qué medida los nuevos comportamientos empresariales se corresponden con el ingreso de nuevos actores a la elite o con la transformación de los preexistentes? Y ¿qué lugar tiene el cambio tecnológico en la consolidación de estos perfiles empresariales que no solo muestran características de mayor concentración sino que también se erigen como prototipo de la posibilidad de persistencia/inclusión en el actual modelo productivo? No podemos dar una respuesta acabada, sino pistas surgidas del análisis de distintas fuentes. ${ }^{12}$ Así, si se tiene en cuenta el origen y las trayectorias de los titulares de grandes explotaciones, podemos hablar de un proceso de recomposición resultante de distintos movimientos: por un lado, el ingreso de actores extra agrarios que entran a la actividad atraídos por las altas tasas de retorno en los últimos diez años; por el otro, la reconversión del perfil de los descendientes de los tradicionales gran-

11 Los censos relevan información sobre explotaciones agropecuarias, pero no permiten reconstruir las relaciones de propiedad y/o control de más de una explotación por parte de una misma persona física o jurídica.

12 Entrevistas en profundidad a diez empresarios grandes, fuentes periodísticas (suplementos rurales de los diarios La Nación y Clarín), entrevistas a informantes clave. 
des propietarios - proceso relacionado con un compromiso más activo y profesionalizado con la gestión de los campos familiares-; finalmente, la movilidad social ascendente registrada entre las franjas superiores de la agricultura familiar pampeana. Como pude constatar en distintas entrevistas, en las experiencias de los actores la adopción de tecnología -en las dimensiones materiales y prácticas señaladasconstituyó el mecanismo que les explica que, partiendo de lugares tan diversos del espacio social, hayan arribado -más allá del volumen de recursos que controlan- a un punto común: una manera de ser productores. En palabras de un entrevistado:

Nada más tener la cabeza abierta, actitud de aprender. Hay profesionales $\mathrm{y}$ hay tipos de escuela primaria y todos son buenos empresarios [...] no es un problema de escala, es un problema de actitud: medir, ensayar, probar...lo mismo hacerlo en gran escala que en maceta, como digo yo (Orlando, noviembre de 2008).

La cuestión no es menor ya que les permite construir representaciones sobre el modelo como uno con potencialidad inclusiva, lo que tiene consecuencias, como veremos, para las creencias y valores que sostienen sus comportamientos políticos, haciéndolos legítimos a sus propios ojos.

\section{Las corporaciones agrarias}

Desde mediados del siglo XIX, la representación de los grandes estancieros pampeanos estuvo en manos de la Sociedad Rural Argentina (SRA), creada en 1866. En su análisis sobre el ruralismo terrateniente, Hora subraya al describir a la SRA la "acusada vocación modernizante, a la vez técnica y política, (que) singularizaba a los promotores de la primera asociación rural del país" (Hora 2009: 25). Para el autor, desde sus orígenes esta entidad manifestó la necesidad de transformar a los grandes terratenientes en "líderes" de una transformación que reconvirtiera el perfil del propio empresariado y el contexto en el que actuaban (Hora 2009: 25). Dicho contexto no solo refería a variables macroeconómicas, de mercado sino también a modelos de producción y tecnología agraria. Así, "cambio y modernización" constituían uno de los rasgos más originales del grupo fundador de SRA, que buscaba enraizarse como representación del conjunto de los terratenientes. Sostiene Hora que el liderazgo de esta elite estaba asentado 
en una "indudable legitimidad" en lo que refiere a su papel social (la prosperidad económica de la cual eran sus actores principales), y a los modos de construcción de poder (articulación de sectores subalternos; alianzas y vínculos con la industria procesadora de materias primas, con el comercio y con las finanzas).

La relación entre esta próspera elite y el régimen político, resaltada por los análisis académicos, se vio complejizada a partir de 1912, cuando una nueva ley electoral (Ley Sáenz Peña) permitió el acceso de grupos hasta entonces excluidos de la política, y en el ámbito rural, se conformó la Federación Agraria Argentina (FAA), expresión de una oposición -terratenientes/colonos- que estructuró políticamente las existentes líneas de fractura de la estructura agraria. En otro trabajo, Hora señala que en ese contexto, la elite no solo se vería enfrentada a la mayor permeabilidad del régimen político a las demandas de los grupos subalternos sino también a un creciente cuestionamiento de su enorme riqueza, particularmente al hecho de que ella deviniera de la propiedad de la tierra (Hora 2005: 72). La mayor heterogeneidad del mapa institucional, la conflictividad agraria (de las cuales la emergencia de FAA daba cuenta) y la complejización de las formas de construcción y agregación de intereses, se profundizaron años más tarde, con la creación en 1936 de la Confederación de Asociaciones Rurales de Buenos Aires y La Pampa (CARBAP), integrada por antiguos socios de la SRA, enfrentados a los capitales norteamericanos que controlaban la industrialización y comercialización de carne. Así, la pretensión de ser articuladora del conjunto de actores de la economía agroexportadora y de encarnar los valores y modelos de nación y sociedad deseable (Palomino 1988), se vieron contestados, y el liderazgo de SRA resquebrajado.

En el plano nacional, y como consecuencia de la industrialización y el crecimiento urbano, la posición del sector agropecuario en la economía fue cambiando; la irrupción del peronismo en 1945 profundizó la pérdida de gravitación económica y social de los grandes terratenientes. Sin embargo, como hemos señalado, dada su posición en la estructura económica, la burguesía agraria y su elite retuvieron para sí la capacidad de negociar y presionar al Estado para obtener ventajas y/o no ser perjudicadas en sus intereses.

El núcleo ideológico de estos grandes productores se organizó en torno a la libertad de los mercados, la subsidiariedad del Estado y 
la salvaguarda de la propiedad privada -principios que organizan sus demandas públicas-, en apelaciones generales a la defensa del "campo" como una unidad y a su rol preponderante para el conjunto de la nación. Estos elementos conformaban un sistema coherente de ideas, fortalecido en la segunda posguerra, por la oposición al peronismo. Plantea Heredia (2003), que el universo ideológico de la elite agropecuaria y de su portavoz principal, la SRA quedó estrechamente asociada al antiperonismo y a la condena de toda forma de populismo. Debe incluirse aquí a las Confederaciones Rurales Argentinas (CRA), entidad que agrupa a CARBAP y otras regionales similares, que comparten esos principios ideológicos, si bien diferenciándose en las estrategias discursivas y de acción privilegiadas (Nun/Lattuada 1991). El tipo de acción corporativa desarrollada se caracterizó en esta etapa por un

ejercicio de influencia personal, el contacto directo con los funcionarios, un profundo conocimiento de los mecanismo formales e informales del proceso de toma de decisiones y, en general, una fuerte presencia en la estructura de poder, derivada de sus estrechos vínculos con otros grandes grupos de intereses (Nun/Lattuada 1991: 65).

En el caso de CRA, con menor acceso a esas redes de influencia, se observaría una mayor inclinación por acciones de confrontación con el Estado y de "presión por choque". Más allá de estas diferencias, las políticas de precios y de impuestos fueron históricamente los puntales de la acción de estas entidades. Este tipo de corporativismo ha buscado recomponer cierto orden de cosas (la contribución a la economía y a la identidad nacional de la actividad agropecuaria), en momentos en que dicho orden está en crisis o amenazado, lo que fue eficaz para bloquear políticas públicas que buscaran incidir globalmente sobre las condiciones en que ha operado el sector agropecuario. En este sentido, es posible trazar un hilo conductor que va desde la pérdida de centralidad del agro frente a la emergencia de otros sectores y actores dinámicos en la posguerra, a la concentración de la acción corporativa en la defensa sectorial y el abandono de aquellas prácticas que construían a los grandes productores como agentes centrales de cualquier proyecto de modernización de la economía y la sociedad nacionales, rasgos que, como mencionamos antes, identificaron en su origen a la SRA. 
Pero no eran solo estas formas de representación de intereses las únicas reconocibles entre las elites rurales argentinas. Si en el país la representación electoral -propia de las mediaciones neocorporativas- no caracterizó sus formas de influencia, sí lo tuvieron en las últimas décadas, y de manera significativa en los '90, las asociaciones profesionales. Ubicadas sobre la expertise técnica y la innovación tecnológica, estas entidades conforman actores importantes para el estudio de los canales de construcción y articulación de los intereses dominantes, así como también para la construcción de un liderazgo social y político, a partir de la restitución y resignificación de la importancia material y simbólica de la tecnología en los imaginarios sociales sobre el progreso.

\section{Retomando las tradiciones: técnica y política}

Hacia inicios de la década de 1960, surge otro tipo de organización con la que comienza a referenciarse la elite agropecuaria: la Asociación Argentina de Consorcios de Experimentación Agrícola (AACREA). Es una red de consorcios de empresarios organizados como grupos de trabajo para intercambiar información y ser asesorados en materia tecnológica, de gestión empresarial, etc. Inicialmente conformada por grupos de la elite pampeana, en los ' 70 comienza a incluir a chacareros. ${ }^{13}$ Aún cuando el proceso no fue fácil, es menester señalar que las transformaciones que había atravesado la estructura agraria -que se profundizaron en las décadas siguientes- habían ido reconfigurando el histórico antagonismo colono/oligarquía, y que espacios como los grupos CREA fueron, con el transcurso del tiempo, estructurando experiencias que llevarían a los propios actores a percibir las líneas de fractura de la estructura social de un modo distinto.

La idea inicial de los fundadores era sencilla: buscar en conjunto la forma de resolver problemas técnicos comunes. La iniciativa retomaba el interés y el impulso dado por los pioneros de la SRA a la innovación técnica y a la transformación de la gestión empresarial, algo

13 El término identifica a una heterogénea capa de productores, que incluye desde productores basados en el trabajo familiar con cierta capacidad de acumulación (homologable a la figura del farmer norteamericano) hasta la pequeña burguesía agraria. En términos políticos, refiere al proceso histórico de lucha de los colonos inmigrantes por el acceso a la propiedad de la tierra, y a la constitución de una identidad definida por oposición a la oligarquía terrateniente. 
que parecía haber perdido vigor en aquella entidad, al menos en la visión de los terratenientes que fundan AACREA. En efecto, como hemos analizado en otro trabajo, los documentos institucionales que recogen discursos de los fundadores son enfáticos en señalar a sus pares que la evolución negativa de la producción y la rentabilidad -recordemos, es la etapa del estancamiento pampeano-, o los problemas que afectaban a sus explotaciones no lograrían ser resueltos simplemente a través de políticas de precios o impuestos. Se requería asimismo de transformaciones técnicas en los procesos productivos, la organización interna de las empresas y la gestión. Así, desde su emergencia, pone en juego al conocimiento experto como principio legitimador de su existencia y Leitmotiv de sus objetivos, generando un ámbito de acción que podía ser sustraído fácilmente de la discusión y el escrutinio político.

Estas apelaciones eran críticas de la eficacia de la acción corporativa tradicional y de la presión política para obtener beneficios, al menos como única estrategia para responder a las situaciones que por entonces se planteaban. Lo que debía cambiar también era la "mentalidad" de esa elite propietaria, que había quedado atrapada en la reacción antiperonista, ubicando en la intervención del Estado populista la raíz de todos los males.

En suma, se necesitaba, en la visión de estos hombres, de una verdadera vocación de liderazgo para transformar el perfil empresarial de la elite agraria para que ella pudiera "ser la punta de lanza de una nueva agricultura", que permitiera al sector agropecuario retomar su lugar en la economía y en la sociedad nacional en un momento histórico -la segunda posguerra- en que un mundo en crecimiento necesitaba alimentos. Ello requería de una nueva manera de entender y practicar la actividad agropecuaria y de una nueva identidad empresarial. Desde sus inicios, esta asociación profesional ${ }^{14}$-como también de otras que surgieron en los '90, como la Asociación Argentina de Productores en Siembra Directa (AAPRESID)- convoca

14 AACREA agrupa actualmente a unos 1800 socios, cuyas empresas superan, en promedio, las 2.500 hectáreas. Originalmente, predominaban los productores ganaderos (y entre ellos, de invernada). Actualmente, ese perfil ha cambiado, integrando entre sus filas a los productores sojeros más importantes. Un análisis de esta organización profesional, los núcleos de su identidad institucional y su relación con la construcción de una clase dirigente, puede verse en Gras (2009). 
al empresariado rural de un modo preciso con incitaciones prácticas a la acción, primero "tranqueras" adentro (a través de la capacitación y la experimentación), y luego "tranqueras afuera". Las primeras han impulsado, a lo largo de los años, cambios en la organización de la producción y en las estrategias desarrolladas por los empresarios, la construcción de redes, la profesionalización de la gestión. Como hemos señalado, estos cambios son parte de la recomposición de las elites agrarias.

Por su parte, las acciones "tranqueras afuera" han buscado conectar a la clase empresarial con el Estado, movilizando otros tipos de recursos y mecanismos de influencia, como el asesoramiento. Si bien esto no es estrictamente novedoso, sí lo es la recurrencia, casi con exclusividad, al conocimiento científico como base y fuente de las interacciones. Con menor centralidad y gravitación económica y política, las elites agrarias encontraban en la ciencia y la modernización lo que -siguiendo a Boltanski/Chiapello (2002)- puede definirse como una lógica legítima de justificación. Pero la legitimidad que lograban como agentes productivos y económicos hegemónicos no era traducible sin más en legitimidad para actuar en otros ámbitos, como el político. En ese marco, ubicamos los comportamientos que la elite fue desplegando en las últimas décadas, a partir de los cuales iría cimentando la asociación entre su liderazgo tecnológico y la construcción de un liderazgo sociopolítico.

Una primera esfera de acción en ese sentido es la que le permite resituarse como actores con proyectos y propuestas, y no sólo como sector que busca defender las posiciones alcanzadas. En esa esfera, el papel de las asociaciones profesionales es central. Con ellas adquiere relevancia la influencia en el diseño y ejecución de políticas públicas -en particular aquellas que moldean las condiciones de producción del sector agropecuario y que inciden en su dinámica de acumulación-; influencia cuya legitimidad es construida a partir de la autoridad que otorga el discurso tecno-científico. Las interacciones entre AACREA y los llamados policy-makers han sido cambiantes a lo largo del tiempo, y en ese sentido los grados de autonomía estatal y la mayor o menor apertura de esos puntos de acceso no son ajenos a las transformaciones en las instituciones estatales y en las características organizativas y perfil de los miembros de AACREA. 
Uno de los ámbitos fundamentales donde AACREA ha desarrollado influencia es el de la política tecnológica. Un ejemplo bastará para ilustrarlo: su participación en la Mesa Directiva del Instituto Nacional de Tecnología Agropecuaria (INTA), principal instrumento del Estado nacional para impulsar innovaciones tecnológicas y productivas, mediante la investigación en desarrollo y extensión. Desde hace varias décadas AACREA integra, mediante un representante, su Consejo Directivo, encargado de fijar las políticas y estrategias globales del organismo. Si bien las corporaciones (SRA, CRA) también tienen presencia en este órgano del INTA, la impronta de AACREA es reconocible en una de las políticas más importantes que ese organismo puso en marcha en la década de 1990, el programa Cambio Rural. Al mismo tiempo, allí se deciden las investigaciones que el INTA financia y luego transfiere a través de las redes de extensionistas a los productores. En esta materia, AACREA ha sido una fuerte militante de la investigación en biotecnologías y de la organización de metodologías de transferencia.

El programa Cambio Rural -cuya población destinataria son pequeños y medianos empresarios- tuvo como premisa la transferencia de tecnologías de producción y de gestión, y una dinámica de implementación semejante a la metodología de los grupos CREA. Este programa es un ejemplo elocuente de la influencia en decisiones que son a la vez estratégicas para los intereses de la elite agropecuaria: articulando con el Estado para establecer prioridades de agenda, y proponiendo la construcción de lo que llaman "redes público-privadas" para promover ciertos cambios sustantivos en el modelo productivo (la transformación de productores en "empresarios", entre las capas de la producción familiar; la identificación de la tecnología y el management como explicación del éxito o fracaso de los productores). Esos cambios se apoyaron en mecanismos de promoción de ciertos modelos organizativos y en la "desatención" de actividades que quedaron desplazadas en el nuevo modelo. Por último, en el ámbito de la innovación tecnológica AACREA y AAPRESID participan en distintas iniciativas como contraparte del aparato estatal de ciencia y técnica.

Todas estas instancias de interacción con las instituciones estatales fueron fundamentales para la construcción de un ambiente económico $-\mathrm{y}$ también político- que favoreció la puesta en marcha de 
cambios que fueron parte importante de la instauración del nuevo patrón de acumulación agraria. Cabe insistir, una vez más, en la doble dimensión de esos cambios -uso de biotecnología, y desarrollo de un tipo de gestión y comportamiento empresarial- y su relación con la construcción de liderazgo de las elites contemporáneas. ${ }^{15}$

Por último, ¿qué implica la emergencia de estas asociaciones profesionales que se asientan sobre su carácter técnico para influir en los procesos decisorios, y que mediante su actividad han sido eficaces en la pretensión hegemónica de construir un perfil de empresariado moderno, a través de mecanismos tan variados como la organización de maestrías de agronegocios, programas de radio, prensa? Es decir, ¿qué implica en relación con la presencia de otro tipo de organización como SRA o CRA? Si bien es cierto que particularmente la SRA evidenció una crisis en su capacidad de representación de intereses en los años '90 (Heredia 2003), ello no implica el reemplazo de un tipo de práctica corporativa por otra. Antes bien conviene pensar en el modo en que ambas convergen -en qué contextos y situaciones- para cimentar la capacidad de influencia de la elite a través de distintos dispositivos de acumulación de poder.

\section{Tranqueras afuera: liderazgo social y político en tiempos de conflicto}

Si bien la intervención en la esfera de la política pública permitió fortalecer el liderazgo político de este empresariado moderno -habían devenido la "punta de lanza" de la nueva agricultura-, la actuación en ámbitos más amplios que el sectorial, era aún restringida.

El contexto que se abre con la crisis de 2001 funcionó como un estímulo potente para la emergencia de preocupaciones al interior de la elite respecto de su rol en la sociedad más amplia. Tras la explosión del régimen de convertibilidad, algunos representantes de las elites agrarias comenzaron a plantearse su lugar en el proceso de sa-

15 Es interesante en este sentido señalar, en contrataste con lo ocurrido con Brasil, el escaso cuestionamiento público y conflictividad respecto de la centralidad de las biotecnologías (Newell 2009). Por otra parte, la relativamente marginal discusión en torno del modelo sojero puede también explicarse por la efectiva construcción de un imaginario -construcción en la que las asociaciones profesionales han jugado un rol central- de continuidad de la Argentina como país agrario, donde el agro vuelve a ofrecer posibilidades de crecimiento y desarrollo. 
lida de la profunda crisis económica, social y política que le siguió. Estas preocupaciones pueden observarse, por ejemplo, en los temas con los que AACREA convocaba en sus congresos, tanto a sus pares como a intelectuales, líderes políticos y religiosos, con alto predicamento ante la opinión pública: en 2001, el lema fue "Comprender, organizarse, actuar"; en 2002 "Somos parte de una Argentina posible" y en 2007 "El campo trabajando más allá del campo". Otro tipo de iniciativas de esta entidad fueron los programas de "Formación de Líderes" y EDUCREA (programa de apoyo a escuelas rurales), a través de los cuales buscaban sensibilizar a los propios empresarios sobre la necesidad de involucrarse activamente en problemáticas sociales, y revertir cierto desinterés por el compromiso político.

Sin embargo, esa vocación no trascendía el ámbito de las interacciones sociales locales y las iniciativas de tono asistencialista, apoyadas en discursos religiosos. Tampoco había en la política gubernamental situaciones que propiciaran otro tipo de ejercicio que el que llevaban adelante SRA o CRA. Cabe mencionar que en 2002 las retenciones a las exportaciones se habían reinstaurado, y que más allá de reclamos puntuales de las entidades, inicialmente la medida no movilizó gran oposición de los empresarios.

Con la presidencia de Cristina F. de Kirchner, el escenario comenzó a cambiar, con medidas como la instauración de cupos de exportación para el control de los precios internos y los aumentos en las alícuotas de las retenciones. A ello se sumó en 2007 la crisis financiera internacional -que incidió en los precios de los commoditiesy en el plano interno, una de las sequías más importantes de las últimas décadas. En marzo de 2008 el Ministerio de Economía anunció un nuevo aumento de las retenciones -llevando dicho impuesto del $35 \%$ al $44 \%$ en el caso de la soja-, dándole un carácter móvil para acompañar las variaciones de los precios internacionales, lo que disparó el conflicto. Durante casi cuatro meses se sucedieron cortes de ruta, movilizaciones y el cese de la comercialización de productos. En julio, luego de que el decreto presidencial fue girado al Parlamento, el Senado rechazó el aumento y las retenciones volvieron a su anterior nivel. Si bien los cortes de ruta cesaron, la movilización de los productores pampeanos continuó con asambleas y diversos actos, que se prolongaron con distinta intensidad durante 2008 y 2009. 
Nos interesa retomar el conflicto por una serie de razones. En primer lugar, porque al plantearse en el espacio público como un problema de distribución de ganancias extraordinarias, se cuestionaba la relación construida por las elites entre su vocación de cambio técnico y modernizadora, y su legitimidad como clase empresarial. En efecto, sus ganancias provenían -afirmaban- de la inversión en tecnologías y no del control patrimonial sobre la tierra. En segundo lugar, porque el conflicto los conectaba ya no solo con aquello que había movilizado principalmente su actuación hasta entonces (la consolidación de un nuevo perfil empresario) sino también con temas (como la distribución de la renta) en relación a los cuales las fuerzas políticas populares los habían denostado históricamente. El conflicto nos interesa especialmente en conexión con esta segunda dimensión: en efecto, ¿si se trata de elites renovadas, modernas (en su propia construcción), cómo se posicionaban políticamente en un espacio público donde se disputaba la distribución de la renta agropecuaria, precisamente en torno a cuya concentración su legitimidad social había sido largamente cuestionada desde que el Estado y la política devinieron más permeables a las demandas de otros sectores?

Es en ese marco que nos interesa abordar las ideas políticas que las elites fueron (re)creando a lo largo del mencionado conflicto, particularmente en referencia a: a) la relación con el Estado, cuestión que la amplia desregulación del mercado en los '90 había quitado del medio como "problema" para el empresariado rural, y b) las formas políticas que su liderazgo productivo y económico requería, lo que involucraba revisar tanto su relación con las capas inferiores de la burguesía, como las formas organizativas hasta entonces adoptadas. Ambos aspectos, que señalaremos brevemente en lo que sigue, se revelaron como los más sustantivos en nuestro trabajo de campo.

\section{La crítica a la política económica}

Este es el nudo principal de la reacción tanto de elite como de la pequeña burguesía rural, y el que menos controversias despierta entre los diversos grupos que componen el llamado "campo". Medidas como el aumento de las retenciones -sin considerar sus impactos diferenciales según el tamaño de las explotaciones- o la creación de la Oficina Nacional de Control Comercial Agropecuario (ONCCA) -a 
través de la cual el gobierno había intervenido en el mercado de exportación, asignando cupos y autorizaciones de venta-, incidían de manera no menor en las ganancias empresariales y en rentabilidad de sus inversiones. Muchos reeditaban las viejas demandas de libre mercado y la desconfianza a la intervención estatal. "La gente se enfureció por el carácter expropiador de las retenciones, y que todo el tiempo te cambien las reglas del juego, así nadie puede producir", nos decía un empresario en una asamblea a fines de 2008. A ello agregaban la crítica a lo que consideraban la falta de racionalidad de las medidas, que habían constituido un freno "artificial" al crecimiento del sector agropecuario.

Ahora realmente (la plata) estaba puesta en la producción, entonces ipararlo artificialmente! Las retenciones lo paran artificialmente... Con un $10 \%$ de retenciones Duhalde levantaba a la Argentina, con un $20 \%$ Kirchner hacía maravillas, con un $30 \%$ dibujaba pajaritos de colores en los techos de todas las casas Es como que fue demasiada avidez por las retenciones (Francisco, febrero de 2009).

La crítica no está solamente basada en la referencia a la situación empresarial sino que también retomaba la de los chacareros, agitando el fantasma de la expulsión de productores -que todavía estaba en la memoria de aquellos- adjudicándola ya no a la lógica del actual modelo agropecuario sino a los desaciertos de la política económica.

Otras veces, la crisis era por varios factores, estaban sí políticas poco favorables para la producción, como el 1 a 1 , pero también te había permitido tecnificarte, y estaban los problemas del clima, de los precios internacionales bajos. En cambio, ahora todas esas variables eran favorables y la política del gobierno provocó esta crisis, donde vamos a ir cayendo, yo no sé cuantos irán a quedar en pie. Deben querer concentrar 4 o 5 para poder controlarlos mejor,

opinaba un pequeño productor participante de la asamblea mencionada. Las voces de los empresarios eran coincidentes:

que un gobierno nacional genere una normativa que destruya las riquezas es absurdo (Gerardo, marzo de 2009).

En segundo lugar, la crítica involucraba el argumento sobre cómo las medidas de gobierno perjudicaban las relaciones virtuosas que el comportamiento de una clase empresarial moderna había cimentado entre el campo y la ciudad. Hablaban así de un tipo de desarrollo que había comenzado a mostrar sus posibilidades de integración social en el interior del país. 
Yo creo que quedó muchísimo en los pueblos. Porque no te olvides que estas empresas que tenían ganancias no es que se iban con lo que estaban ganado, pagan lo que se llama impuesto a las ganancias. O sea que en la medida en que vos ganás, pagás, no es que te llevas la ganancia. Y básicamente la gente que vive en el interior y vive del campo, en general reinvierte en su zona. Es muy común que se reinvierta hasta el $100 \%$, es mucho más probable que en los grandes conglomerados urbanos haya gente ahorrando en pesos, fuera de su país o en dólares, que en el interior. En el interior compras un terreno, edificas una casa, la gente compra dos vacas más, todos crecen, por eso es inconcebible que no se defienda eso (...) ha dejado un movimiento importantísimo de gente, tremendo. Y bueno cuando empieza a aflojar, empieza a aflojar todo el consumo local, y está bien, habrá menos ricos, menos riqueza, pero también va a haber más pobres, de eso no tengo dudas (Francisco, octubre de 2008).

Otro rasgo, derivado del anterior, fue asimismo subrayado de manera sistemática a lo largo del conflicto, por los dirigentes agropecuarios, sus representados y la prensa: esa misma riqueza que el "campo" producía y reinvertía localmente, impulsando el bienestar local, también llegaba a los grandes aglomerados urbanos, a través de los planes sociales, financiados con las retenciones. La crítica era que, además de excesivas, las retenciones habían servido, en manos de "una clase política corrupta", no a los fines inicialmente previstos, sino a consolidar el clientelismo y la construcción de formas de control social de los actores económicos (mediante subsidios) que atentaban contra las formas republicanas de gobierno:

Mirá, con 90 mil millones de pesos que entraron por cuatro años de retenciones, si hubiesen estado aplicados exclusivamente a la pobreza y a la indigencia, hoy en Argentina no habría ni pobres ni indigentes (Gastón, noviembre de 2008).

Para finalizar este punto diremos que estos discursos sobre el modelo de desarrollo están sustentados en creencias muy generales que pueden movilizar, como se observa, voluntades distintas. Aun así, interesa subrayar -como se advierte en los distintos testimonios- que los entrevistados asignan a las retenciones un carácter anteriormente no presente en sus reacciones corporativas: esto es, a sus ojos perjudican un proceso virtuoso donde el cambio técnico podría asociarse al crecimiento económico y al desarrollo social. Esta forma de concebir el papel del cambio técnico no se interroga por las mediaciones que ligan las distintas dimensiones y la medida en que ellas son construidas y disputadas socialmente. 
El crecimiento que las economías locales observaron luego de 2002 son para la elite una muestra acabada de cómo el modelo contiene mecanismos de distribución de la riqueza, ${ }^{16}$ desde esa certeza plantean críticas a la clase política: para ellos, las retenciones no habían contribuido a mejorar la situación social de otros sectores sino a fortalecer manejos clientelares. Así, se presentaban a la sociedad entrelazando el reclamo por la renta con otro "cívico" por las formas republicanas. En ese contexto, para los entrevistados comienza a plantearse la necesidad de una representación política propia que asegurara sus intereses y la consideración de sus puntos de vista en las políticas del Estado.

\section{Crítica a la clase política y la apuesta por un programa propio}

El conflicto por las retenciones movilizó críticas al partido de gobierno y su manejo del Estado, tanto de la burguesía y sus elites rurales como de sectores urbanos, reeditando de manera inédita representaciones clasistas y lógicas binarias que el país había conocido décadas atrás y que parecían perimidas (Gras/Hernández 2009; Svampa 2008). No es nuestra intención aquí profundizar en ellos sino en las ideas que sobre la política y la relación de la elite agraria con el Estado pueden leerse a través del prisma que el conflicto ofrece.

Si bien la crítica de los empresarios se concentraba en el partido de gobierno, también alcanzaban a los opositores. En otras palabras, la relación con la clase gobernante en sentido amplio fue auscultada, en la medida en que los grados de autonomía que ella adquiere en distintos momentos históricos intervienen de manera directa en las capacidades concretas de los actores agrarios -en particular de sus grupos dominantes- para asegurarse, a través de la política pública, las condiciones de su reproducción y expansión.

Es en ese punto donde empieza a ser discutida la necesidad de alguna otra forma de acción en defensa de los intereses del sector, además de las corporativas. Hay allí dos discusiones que solo podremos mencionar brevemente. La primera tiene que ver con la medida en que el actual mapa institucional del sector agropecuario asegura la representación de los intereses de sus actores dominantes. Se plan-

16 Este es un punto de controversias con otras miradas y representaciones sobre el actual modelo agrario en Argentina, véase Gras/Hernández (2009). 
tea así en las asambleas y documentos de distintos grupos que participan de los debates, la necesidad de una forma organizativa (que algunos llaman "la $5^{\circ}$ gremial") que trascienda la lógica de las representaciones actuales, asentadas sobre las líneas de fractura de la estructura social. Numerosos entrevistados han sostenido que esos clivajes ya no son centrales, por lo que el "sector" debiera encontrar una forma de representación donde la "diversidad" esté contenida. En estas ideas, el campo de poder interno es concebido como plural pero no antagónico. Esa construcción implica también definir sus límites en el plano simbólico: al hablar de "sector" nuestros entrevistados excluyen a los grupos campesinos que están presentes en el agro argentino, planteando que ellos no son parte de la política agraria sino que deben ser atendidos por políticas sociales. Pero la exclusión no es solo el no reconocimiento de los campesinos como sujetos ligados productivamente a la tierra: en algunas situaciones y contextos, puede asumir otras dimensiones -dramáticas- como reflejan los violentos desalojos de campesinos en el norte de Córdoba y en Santiago del Estero.

La segunda discusión refiere a la medida en que las estrategias para mantener/ampliar su capacidad de influencia en la vida pública y política debería incluir la participación electoral. En varias asambleas se dio ese debate, que puede resumirse en dos posturas: continuar con la acción gremial y la búsqueda de acuerdos formales y/o informales con el gobierno, o bien, involucrarse en la dinámica partidaria, ampliando la base de apoyo política con la búsqueda de aliados (grupos de desocupados desplazados del entramado de poder del actual gobierno, clases medias del interior del país).

Tenemos temas que hay que atender ya por lo cual seguramente hay que salir a cortar rutas pero también hay que trabajar para adelante. Tenemos que participar sí o sí en política porque este es un problema político. No lo hemos hecho antes y el no haber participado en política es lo que transformó nuestra actividad, nuestra vida, nuestro modo de vivir en una porquería, porque los políticos son una manga de chorros y son los que nos están gobernando. Para eso tenemos que ir a cada partido, antes de las elecciones, para formar el candidato, o bien para poner un candidato propio, para comprometerlos en qué van a hacer en el caso agropecuario cuando sean gobierno,

sostenía un empresario en una asamblea a principios de 2009. 
En tal sentido, al definir al conflicto como "político" -y ya no sólo "económico" como había sido inicialmente- los empresarios hacían referencia en primer lugar al hecho que la trama institucional existente (sus corporaciones) no lograba articular una comunicación institucional más o menos previsible con las autoridades. En las asambleas se escuchaban críticas veladas o explícitas al modo en que ellas ejercían su representación en el conflicto y, a lo que entendían, se revelaban como los límites de la discusión y negociación sectorial enmarcada en los mecanismos clásicos (audiencia con autoridades, negociación con ministros). En segundo lugar, la definición del conflicto como político hacía referencia a la necesidad, que comenzaban a plantearse, de acceder a los mecanismos de reclutamiento y formación de la clase política, "formar" sus propios dirigentes políticos. Al respecto, uno de los productores agropecuarios más grandes del país nos señalaba:

yo no creo para nada en un partido agrario, esa no es la idea [...] lo que entiendo es que nosotros tenemos que darles influencia positivamente, la mayor cantidad de los partidos políticos para que muchos de los que se dedican sanamente a la política puedan por lo menos escuchar y tratar de entender nuestra visión de una Argentina integrada donde creemos que la agro industria tiene mucho que aportar a las generaciones posteriores de todos los argentinos [...] es la lógica de tratar de buscar que muchos políticas de distintos partidos entiendan estas cosas que pensamos nosotros, entonces darle un marco ideológico (entrevista, marzo de 2009).

La estrategia adoptada (cuya dinámica y efectos es aún pronto para sopesar adecuadamente) fue participar electoralmente, incorporándose a distintos partidos de la oposición. Así, en las elecciones de junio de 2009 en las que se renovaron parcialmente el parlamento nacional y algunas legislaturas provinciales, varios "agrodiputados" obtuvieron sus bancas. En el marco de una crisis política en ciernes en el país y, en el ámbito rural, de cambios en el escenario que permitió el crecimiento espectacular del complejo sojero en los últimos años, sus actores principales se preguntan -por primera vez al menos desde la transición democrática abierta en 1983- por la necesidad de una representación electoral, y discuten nuevas formas de participación política, que traduzcan y hagan efectivo lo que para ellos es evidente: la visibilidad que alcanzaron los coloca en una situación que les demanda encontrar el modo en que su poder económico se traduzca en poder político. En ese marco, cobran sentido las actividades que desde las 
asociaciones profesionales vienen realizando, como la formación de líderes locales o los emprendimientos de responsabilidad social empresaria. En ellas va construyéndose un etos que orienta y da sentido a la acción, que les va permitiendo pensarse como una clase dirigente y un factor de poder, tal como se refleja en las opiniones de un integrante de la elite:

Claramente somos el poder político más importante que tiene la Argentina y el sector con mayor capacidad de movilización, increíblemente. Además de tener nuestro poder económico, aunque no esté puesto al servicio político todavía. Está más puesto al servicio de armar un poder político pero queremos ver cómo tiene que ser el modelo de ese movimiento para poder ayudar a que todas estas ventajas comparativas generen más riqueza. Necesitamos relacionarnos mejor con el movimiento político, con los movimientos sociales, con la sociedad urbana, con la universidad (entrevista, marzo 2009).

En el inicio del siglo XXI, el campo vuelve a demandar un lugar en la distribución del poder acorde a su capacidad para producir riquezas. En este trabajo pretendimos acercarnos a algunos de los rasgos que singularizan las prácticas de sus actores dominantes, observando algunas de las relaciones sociales y políticas que privilegian.

Los eventos recientes no son meramente una demanda específica por una medida económica. También se desplegaron, con todas sus tensiones y contradicciones, dimensiones complejas para pensar las relaciones entre elites económicas, clase política, desarrollo y democracia. En efecto, la actual elite se define por la consolidación de una base técnico-productiva y empresarial moderna que no tiene a la propiedad de la tierra como resorte exclusivo de su poderío. Pero solo en los últimos años, y particularmente en el marco del conflicto con el gobierno, comenzaron a plantearse la traducción de su capital económico en capital político; la insospechada movilización que lograron -de otros actores agrarios como los chacareros, de grupos urbanos, en particular en las localidades del interior del país- les mostró -a otros actores, como los partidos políticos y a ellos mismos- el liderazgo que podían ejercer.

Por primera vez en la historia, ese liderazgo parece dar un lugar significativo a la construcción de conexiones institucionales en la arena pública y político-democrática. Pero también puso en evidencia que el modelo socio productivo que dinamizan no tiene los mismos 
efectos de inclusión para todos los actores. Ese modelo que busca consolidarse y legitimarse como hegemónico en la arena pública puede ser sometido también a la crítica en ese mismo espacio.

\section{Bibliografía}

Boltanski, Luc/Chiappello, Eve et al. (2002): El nuevo espíritu del capitalismo. Madrid: Akal.

Gras, Carla (2009): "El nuevo empresariado agrario: sobre la construcción y dilemas de sus organizaciones". En: Gras, Carla/Hernández, Valeria A. et al. (comps.): La Argentina rural. De la agricultura familiar a los agronegocios. Buenos Aires: Biblos.

Gras, Carla/Hernandez, Valeria A. (2008): "Modelo productivo y actores sociales en el agro argentino". En: Revista Mexicana de Sociología, 70, 2, pp. 227-259.

- (2009): "El fenómeno sojero en perspectiva: dimensiones productivas, sociales y simbólicas de la globalización agrorrural en la Argentina", en Gras, Carla/Hernández, Valeria A. et al. (comps.): La Argentina Rural. De la agricultura familiar a los agronegocios. Buenos Aires: Biblos, pp. 15-37.

Heredia, Mariana (2003): "Reformas estructurales y renovación de las elites económicas en la Argentina: estudio de los portavoces de la tierra y el capital". En: Revista Mexicana de Sociología, 65, 1, pp. 77-115.

- (2005): La sociología en las alturas. Aproximaciones al estudio de las clases/ elites dominantes en la Argentina (Apuntes de Investigaciones del CECYP, año IX, $\left.\mathrm{n}^{\circ} 10\right)$. Buenos Aires: CECYP.

Hernández, Valeria A. (2007): "El fenómeno económico y cultural del boom de la soja y el empresariado innovador”. En: Desarrollo Económico, 47, 187, 331-365.

Hora, Roy (2005): La burguesía terrateniente: Argentina, 1810-1945. Buenos Aires: Capital Intelectual.

- (2009): Los estancieros contra el Estado. La Liga Agraria y la formación del ruralismo politico en la Argentina. Buenos Aires: Siglo XXI.

Newell, Peter (2009): "Bio-Hegemony: The political economy of agricultural biotechnology in Argentina”. En: Journal of Latin American Studies, 41, pp. 27-57.

Nun, José/Lattuada, Mario L. (1991): El gobierno de Alfonsín y las corporaciones agrarias. Buenos Aires: Manantial.

Obschatko, Edith S. de (2003): El aporte del sector agroalimentario al crecimiento económico argentino, 1965-2000. Buenos Aires: IICA.

O’Donnell, Guillermo (1977): "Estado y Alianzas en la Argentina, 1956-1976". En: Desarrollo Económico, 16, 64, pp. 523-554.

Palomino, Mirta L. de (1988): Tradición y Poder: La Sociedad Rural Argentina (1955-1983). Buenos Aires: CISEA-GEAL.

Svampa, Maristella (2008): Cambio de época. Movimientos sociales y poder político. Buenos Aires: Siglo XXI. 